\title{
THOUGHTS
}

\section{Possible intentions and the doctrine of double effect}

\section{Intentions possibles et la doctrine du double effet}

\author{
C. Frugé \\ 106, Somerset Street, 5th Floor, NJ 08901 New Brunswick, USA
}

Received 8 October 2018; accepted 1st December 2018

Available online 25 January 2019

\section{KEYWORDS}

Doctrine of double effect; Intentions; Justification; Modality; Permissibility

\section{MOTS CLÉS}

Doctrine de double

effet ;

Intentions ;

Justification ;

Modalité ;

Licéité

\begin{abstract}
Summary Under the standard formulation of the Doctrine of Double Effect, an act is permissible only if it is the result of an intention to do good and not the result of an intention to do bad. Many find that this absurdly ties the act's permissibility to the agent's character and not to features of the act itself. In light of such criticism, some philosophers have reformulated the doctrine so that it holds that an act is permissible given that it results from an intention to do good by some agent. I argue that this appeal to possible intentions to do good fails. There is no modal or moral reason to privilege intentions to do good over those to do bad, and without privileging them, this version of the Doctrine of Double Effect leads to contradiction. In many scenarios, if a possible intention to do good is considered to be sufficient for permissibility, then in that same scenario a possible intention to do bad should be sufficient for impermissibility. However, one and the same act can have both possible intentions to do good and possible intentions to do bad. Thus, the principle leads to the contradictory ruling that one and the same act is both permissible and impermissible.
\end{abstract}

(c) 2018 Elsevier Masson SAS. All rights reserved.

Résumé Selon la formulation standard de la doctrine du double effet, un acte n'est admissible que s'il résulte d'une intention de faire le bien et non d'une intention de faire le mal. Beaucoup trouvent que cela lie de manière absurde la validité d'un acte au caractère de l'agent et non aux caractéristiques de l'acte lui-même. À la lumière de ces critiques, certains philosophes ont reformulé la doctrine de sorte qu'elle considère qu'un acte soit permis s'il résulte d'une intention de faire le bien par un agent. Je soutiens que cet appel aux intentions possibles de faire le bien est un échec. II n'y a pas de raison modale ou morale pour privilégier les intentions

E-mail address: Christopher.Fruge@rutgers.edu 
de faire le bien par rapport à celles de faire le mal. Sans les privilégier, cette version de la doctrine du double effet conduit à la contradiction. Dans de nombreux cas, si une éventuelle intention de faire le bien est jugée suffisante pour permettre la licéité, alors, dans ce même scénario, une éventuelle intention de faire le mal devrait suffire à l'inadmissibilité. Pourtant, un même acte peut être lié à la fois à des intentions de faire le bien et à des intentions de faire le mal. Ainsi, ce principe conduit à la conclusion contradictoire selon laquelle un même acte est à la fois admissible et interdit.

(c) 2018 Elsevier Masson SAS. Tous droits réservés.

The Doctrine of Double Effect (DDE) traditionally holds that an act is permissible only if the agent intends its good effects and not its bad effects. However, this formulation leads to apparently absurd results. For instance, the principle holds, on the one hand, that it is impermissible for a doctor to inject a lethal dose of morphine with the intention of killing a patient whose pain is so great that it would be better for her or him to die. At the same time, DDE holds that it would be permissible for the doctor to inject a lethal dose if she or he merely foresaw but did not intend the patient's death.

Some ethicists have tried to avoid these results by revising the doctrine so that an act's permissibility turns on whether it could have been the result of an intention to bring about its good effects and not its bad effects. This revised principle holds that an act is permissible given that there is a possible intention to do good that brings about that act, even if the act is in fact a result of an intention to do bad. Accordingly, it is permissible for the doctor to inject a lethal dose of morphine with the intention that the suffering patient dies, so long as it is possible that the doctor could so act without intending the patient's death but rather because they intend something good, such as relieving the patient from pain.

In this paper, I show that this revised principle in conjunction with a parallel principle that links impermissibility to possible intentions to do bad leads to contradiction. Therefore, proponents of the possible intentions version of the DDE must privilege possible intentions to do good over those to do bad. However, I argue that there is no modal or moral reason to do so. Therefore, the possible intentions version of the DDE must be abandoned.

The usual understanding of the DDE is that it holds that an act is permissible only if it results from an intention to bring about its good effects rather than its bad effects. This allows that one can foresee that some bad will result as the action's side effect, so long as one does not intend to bring it about. According to this principle, surgeons can permissibly cut out an ailing appendix, even though they can foresee that doing so will cause their patient pain, so long as they intend that the patient be saved from a burst appendix and do not intend that the patient feel the surgery's foreseeable pain.

Let us call this view DDE-Actual, because it is formulated in terms of the agent's actual intention:

\section{DDE-Actual: An act is permissible if and only if}

1) it is the result of an actual intention to bring about the good effects of an act and not the result of an intention to bring about the bad effects of the act-either as ends or means to the good effects,

2) and conditions $c_{1}, c_{2}, \ldots c_{n}$ are met, where conditions $c_{1}, c_{2}, \ldots c_{n}$ are further conditions that do not have intentionality as part of their content-such as a proportionality condition between good and bad or a necessity condition on there being no less harmful way of achieving the desired goal [1, p. 43].

Clause (2) covers what I call 'non-intentionality involving conditions', and I remain non-committal as to what they are.

DDE-Actual holds that an act is permissible if and only if all of the non-intentionality involving conditions are met and the agent intends to do good and does not intend to do bad. Given that an act is permissible if and only if it is not impermissible, then this version of the DDE also holds that an act is impermissible if and only if one of the non-intentionality conditions are not met or that act results from an intention to do bad. Therefore, it is sufficient for an act to be impermissible that the agent acts with an intention to do bad. At least, all of this is so on the assumption that one can intend either good effects or bad effects, but one cannot intend neutral effects. For simplicity, I make this assumption, but everything I say in this paper can be tweaked to accommodate intending neutral effects.

As stated, DDE-Actual is an absolutist prohibition against intending bad in that if one does not intend the good effects of one's action, then one acts impermissibly-regardless of the benefits one's act may bring. However, one might believe, for instance, that an act is permissible despite the fact that the agent intends the bad effects if it is the case that the good outcomes of the act enormously outweighs the bad outcomes. An aide might intend to annoy the president by preventing them from launching a nuclear missile but this act might be permissible if it saves many lives. We can formulate DDE-Actual without invoking an absolutist prohibition:

DDE-Actual (Non-absolutist): An act is permissible if and only if

1) it is the result of an actual intention to bring about the good effects of an act and not the result of an intention to bring about the bad effects of the act-either as ends or 
means to the good effects, 2 ) and conditions $c_{1}, c_{2}, \ldots c_{n}$ are met.

Or

3) the act is the result of an intention to bring about the bad effects but conditions $c_{a}, c_{b}, \ldots c_{m}$ are met, where $c_{a}$, $c_{b}, \ldots c_{m}$ are conditions not having intentionality as part of their content.

We can think of $c_{a}, c_{b}, \ldots c_{m}$ as threshold conditions such that if they are satisfied then so much good is done in a proportional and necessary manner that the act is permissible even if it results from a bad intention. According to the nonabsolutist version of DDE-Actual, an act is impermissible if and only if it results from an intention to do good but one of $c_{1}, c_{2}, \ldots c_{n}$ is not met or it results from an intention to do bad and one of $c_{a}, c_{b}, \ldots c_{m}$ is not met. For simplicity, I mostly consider absolutist versions of the DDE, but everything I say can be tweaked to apply to non-absolutist variants.

Many philosophers find DDE-Actual to be absurd because there are cases where two acts differ only in the agent's intention, and DDE-Actual rules that one of them is impermissible [2-4]. I present some of these cases below. For all of them, it should be assumed that they satisfy the absolutist non-intentionality involving conditions $c_{1}, c_{2}, \ldots c_{n}$ but not the non-absolutist non-intentionality involving conditions $c_{a}, c_{b}, \ldots c_{m}$, which ensures that both the absolutist and non-absolutist versions of DDE-Actual rule that the act resulting from an intention to do bad is impermissible, but the act resulting from an intention to do good is permissible. The only relevant difference between the cases is the difference in intention.

One set of cases revolves around lethal doses of pain relief medication $[3,5]$ :

- Intentional Death Lethal Dose: Patient is in horrendous pain such that their death would be better for them. Intentional Death Doctor injects a lethal dose of morphine intending that Patient die in order that they be relieved from pain, thereby also foreseeing that they will die;

- Foreseen Death Lethal Dose: Patient is in horrendous pain such that their death would be better for them. Foreseen Death Doctor injects a lethal dose of morphine intending that Patient be relieved from pain, with the foreseen effect that they will die.

According to DDE-Actual, Intentional Death Doctor's act-at least as they intended it-is impermissible because they intend to produce the bad of Patient's death, while Foreseen Death Doctor's act is permissible because they intend to produce the greater good of relieving Patient from pain. Many, however, think this is absurd. As J.J. Thomson puts it:

According to [the DDE], the question whether it is morally permissible for the doctor to inject a lethal drug turns on whether the doctor would be doing so intending death or only intending relief from pain...If the only available doctor would inject to cause the patient's death, or is incapable of becoming clear enough about her own intentions to conclude that what she intends is only to relieve the patient's pain, then-according to [the DDE]-the doctor may not proceed, and the patient must therefore continue to suffer. That cannot be right...I suggest that [a given doctor's intention in acting] has no bearing on whether it is morally permissible for her to act $\left[3\right.$, p. 515-6]. ${ }^{1}$

The acts only differ with respect to the doctor's intention. How can the permissibility of the act of giving the drug turn on the doctor's aims?

Another set of cases revolves around military strikes:

- Intentional Death Airstrike: Intentional Death Pilot bombs a munitions factory where there are nearby innocent civilians with the intent that they die, foreseeing that the destruction of the factory will cripple the aggressor nation's war effort and save many more lives;

- Foreseen Death Airstrike: Foreseen Death Pilot bombs a munitions factory where there are nearby innocent civilians with the intent to cripple the aggressor nation's war effort and thereby save many more lives, foreseeing that the civilians will die.

According to DDE-Actual, Intentional Death Pilot's act is impermissible-at least as they intended it-because they intend the civilians' deaths, while Foreseen Death Pilot's act is permissible because they intend to end the war and in so doing will save proportionately more lives. But many find this result to be absurd. It should not make a difference to the permissibility of the bombing which pilot happens to be flying. As James Rachels puts the objection, "A pure heart cannot make a wrong act right; neither can an impure heart make a right act wrong' ' 2 , p. 142].

We need not appeal to brute intuition alone in holding that DDE-Actual gets the wrong results. F.M. Kamm has formulated a variety of 'Four-Step Arguments' that serve to justify our intuitive judgments in the lethal dose for pain relief cases. The primary argument is as follows:

(A) Doctors may permissibly relieve pain in a patient (e.g., by giving morphine), even if they know with certainty that this will cause the death of the patient as a foreseen side effect, when death is a lesser [bad] and pain relief is a greater good for the same person and only the morphine can stop the pain. [This is the Foreseen Death Lethal Dose case.]

(B) Doctors may permissibly intentionally cause other lesser [bads] to patients when these are the necessary means to their medically relevant greater good (e.g., a doctor might permissibly intentionally cause a patient pain temporarily if only this would keep the patient from falling into a permanent coma).

(C) When death is a lesser [bad] for a person, it is not morally different from other lesser [bads].

(D) Therefore, when death is a lesser [bad] and pain relief is a greater good for the same person (just as it is in Step 1 ), it is also permissible to intentionally cause death, or assist in its being intentionally caused, when it alone can stop pain. (For example, we could give morphine, which itself no longer relieves pain, in order to induce death.) [This is the Intentional Death Lethal Dose case] $\left[7\right.$, p. 57-8]. ${ }^{2}$

This argument suggests that Intentional Death Doctor's act is permissible if Foreseen Death Doctor's act is per-

\footnotetext{
1 Quoted in [6]. The editorial changes are FitzPatrick's.

2 I have made some minor changes for presentational purposes.
} 
missible. The DDE is formulated precisely to allow that the latter's act is permissible. Hence, it seems that the proponent of the DDE must allow that Intentional Death Doctor's act is permissible. But DDE-Actual precludes Intentional Death Doctor's act from being permissible, again getting the wrong results. ${ }^{3}$

DDE-Actual makes the moral permissibility of an act depend on the particular intentions of the agent who happens to be acting. Many have objected that it thereby conflates moral assessment of an act with moral assessment of an agent's character [2, p. 141]. While moral judgment of character is important, it does not bear on the permissibility of the act itself. In light of such criticism, William FitzPatrick $[6,8,9]$ has formulated a version of the DDE that appeals to possible intentions to do good in order to try and tie permissibility to the nature of the act and not that of the agent. FitzPatrick understands permissibility as turning on whether the act could have resulted from some possible intention of some agent. He says that according to the DDE:

An act of the relevant type (e.g., bombing the munitions plant) is permissible just in case there exists a justification for it in terms of a sufficiently worthy end that can be pursued through so acting without intending anything illicit as a means [6, p. 320].

As FitzPatrick puts its elsewhere:

The DDE. . is best understood as a constraint on the justification of action, having to do not with any particular agent's actual intentions but with the intentions that would be involved in performing a certain type of action for the reasons provided by a proposed justification [8, p. 102].

Similarly, he also says:

The idea is (roughly) that it is a condition of adequacy on any justification $\mathrm{J}$ of action $A$ that a good agent could act well in performing $A$ for the reasons given in $J[9$, p. 191].

According to FitzPatrick, an act is permissible given that it could have resulted from an intention to do good.

Let us call this version DDE-Possible and put it as follows:

DDE-Possible: $A$ token act is permissible if and only if

1) it is possible that an act of its type be the result of an intention by some agent to produce the good effects and it not be the result of an intention to bring about the bad effects-either as ends or means to the good effects,

2) and conditions $c_{1}, c_{2}, \ldots c_{n}$ are met.

For the non-absolutist version, we would also add: Or

3) there is no possible intention to bring about the good effects-that is, there are only possible intentions

\footnotetext{
3 This sort of argument is less plausible in the airstrike cases because it is not the case that all the harms and benefits accrue to one and the same person.
}

to bring about the bad effects-but conditions $c_{a}, c_{b}, \ldots c_{m}$ are met. ${ }^{4}$

Just considering the absolutist version, DDE-Possible holds that an act is permissible if and only if the nonintentionality involving conditions are met, and there is some possible intention to do good that could have led to the action. An act is impermissible, according to this principle, if and only if either the non-intentionality conditions are not met or it is not possible that the act results from an intention to do good.

DDE-Possible on either version is crafted to avoid the alleged absurdities of DDE-Actual. Intentional Death Doctor's act of killing the patient is permissible because there is some possible agent with a possible intention to do good, namely Foreseen Death Doctor. Intentional Death Pilot's act is also permissible because there is some possible agent with a possible intention to do good, namely Foreseen Death Pilot. In applying DDE-Possible to the pilot cases, FitzPatrick says:

The actual intentions of [Intentional Death Pilot] are irrelevant to the permissibility of flying the mission... what matters is just whether there is an otherwise sufficient justification $J$ for flying such $a$ mission. . such that a good agent could fly such a mission for the reasons given in $J$ without thereby intending harm to innocents and acting badly. This of course yields the same verdict on permissibility as in the [Foreseen Death Airstrike] case: the mission against the munitions plant is permissible, period, for the reasons given in the justification and because a good agent could act on those reasons without being involved in bad intentions and acting badly [9, p. 192].

DDE-Possible gets the desired verdicts in the cases that posed problems for DDE-Actual. However, DDE-Possible faces problems of its own.

Let us just consider the absolutist version of DDEPossible. It holds that a necessary condition on permissibility is that there is a possible intention to do good. This entails that a sufficient condition for an act to be impermissible is the absence of any such possible intention to do good. However, the principle also suggests something stronger, namely that possible intentions to do bad are sufficient for impermissibility:

DDE-Possible*: A token act is impermissible if and only if

$\left.1^{*}\right)$ it is possible that an act of its type be the result of an intention by some agent to produce the bad effects-either as ends or as means to the good effects-and it not be the result of an intention to produce the good effects,

$\left.2^{*}\right)$ or one of $c_{1}, c_{2}, \ldots c_{n}$ is not met.

\footnotetext{
${ }^{4}$ Again, I am assuming there are always good and bad effects of an action, given that those are the cases where the DDE applies at all. And, perhaps idealizing, I am assuming that one must intend either good or bad effects when one intends to act.
} 
Later in the paper I show how DDE-Possible leads to DDEPossible*, but first I want to show how their combination leads to trouble.

DDE-Possible and DDE-Possible* together lead to contradiction in that they allow one and the same act to be both permissible and impermissible. This is so even in cases where DDE-Possible is supposed to improve upon DDE-Actual. Take the Intentional Death Lethal Dose case. DDE-Possible is constructed to allow that the act in this case is permissible, given that Foreseen Death Lethal Dose is possible and thus there is a possible intention to do good behind the act. But given that Intentional Death Lethal Dose itself obtains, then there is a possible intention to do bad behind the act, namely the actual intention to cause death. Hence, DDE-Possible* rules it as impermissible. We thus have the contradictory ruling that the act both is and is not permissible. The same holds in the Intentional Death Airstrike case. DDE-Possible rules that Intentional Death Pilot's action is permissible given that Foreseen Death Pilot is a possible pilot with an intention to do good that results in the act. But Intentional Death Pilot acts with an actual intention to do bad, and thus there is a possible intention to do bad that could result in the act. Therefore, DDE-Possible* rules that the act is impermissible, while DDE-Possible rules that it is permissible. The two principles lead to contradiction.

Perhaps one might object that the real content of the DDE is not that one must intend the good but rather simply that one not intend the bad [5]. DDE-Possible would then hold that an action is permissible if and only if it is possible that there is no intention to do bad and conditions $c_{1}$, $c_{2}, \ldots c_{n}$ are met. But even if DDE-Possible were formulated as above, then DDE-Possible* would just have to become the slightly modified DDE-Possible ${ }^{* *}$ that holds that an action is impermissible if and only if it is possible that there is no intention to do good or one of $c_{1}, c_{2}, \ldots c_{n}$ is not met. And the same cases of Intentional Death Lethal Dose and Intentional Death Airstrike where there are intentions to do bad suggest cases where it is possible there is no intention do good. The pilot might have no intention to help the war effort. The doctor may only enjoy killing. The ensuing arguments for DDE-Possible* equally serve as arguments for DDE-Possible** with only the slightest of changes. I ignore the alternate DDE-Possible and DDE-Possible** in what follows.

On pain of allowing for contradiction, the proponent of DDE-Possible must require that intentions to do good are privileged over those to do bad. They must deny DDEPossible* by holding that possible intentions to do good make a difference to permissibility, whereas possible intentions to do bad do not. But possible intentions to do good cannot have such an asymmetric relevance over possible intentions to do bad. Defending this claim is the task for the rest of the paper. First, I argue that intentions to do good are not modally privileged over those to do bad. Second, I argue that they are not morally privileged, or at least proponents of DDE-Possible have given us no reason to think so.

As for modal status, a given act could possibly result from both intentions to do good and to do bad. Moreover, in many cases the intention to do bad is modally closer than the intention to do good. Take Intentional Death Airstrike. If this case is actual, then there is a possible world described by Foreseen Death Airstrike where the same type of act is the product of an intention to do good. But there is also a possible world where there is an intention to do bad lying behind this type of act, namely the world of Intentional Death Airstrike. Indeed, this case is actual relative to itself, hence the nearest world with an intention to do bad is much closer than the nearest world with an intention to do good. The same reasoning holds for the Intentional Death Lethal Dose case and for any case where the actual intention is one to do bad.

There is no modal reason to privilege only intentions to do good, but might there be a moral reason to privilege them? Let us return to the motivation for positing DDE-Possible. FitzPatrick holds that possible intentions to do good reveal a justification for the act, and such a justification is necessary and sufficient for permissibility:

The DDE does not in fact link the moral permissibility of an act with the token intentions with which a given agent would be acting. Rather, it links the permissibility of a certain type of act with the existence of a justification in terms of a sufficiently worthy end that can be pursued through so acting without intending anything illicit as means [6, p. 319].

In terms of the Intentional Death Airstrike case, FitzPatrick believes that although the pilot may have acted with bad character [8, p. 110], there still exists a sufficient justification for the bombing in terms of "its military significance, such that one could so act for the justifying end without intending the deaths of innocents" [6, p. 320].

FitzPatrick spells out the connection between justification, permissibility, and intentions to do good by way of the following argument:

- a justification for an action is adequate only if a good and well-informed agent could act well (i.e., at least not act badly) in performing the action because of that justification for it;

- intending significant harm toward innocents as a means or end is deeply morally problematic as such, which typically makes acting on such an intention constitute acting badly;

- so, an adequate justification of action typically cannot be such that an agent who performed the action because of that justification would be engaging in the intention of significant harm toward innocents as a means or as an end;

- there is thus a constraint on the justification of action such that an action typically cannot be justified (shown to be permissible) by showing it to be an efficient means to a good end in cases where the action constitutes such a means precisely by virtue of being significantly harmful to innocents [8, p. 102-5].

The first premise holds that in most cases it is a necessary condition on permissibility that there is a potential justification for the action such that the agent could act in accordance with good character by acting on that justification. Intending to do bad is such that in most circumstances one cannot act on an intention to do bad while acting with good character. Thus, barring exceptional circumstances, a justification for an action cannot involve an intention to do bad. Hence, in normal circumstances an action is impermissible if there is no justification that does not appeal to an intention to do bad. 
While this argument officially supports the claim that a possible intention to do good is necessary for permissibility, it is plausible to suppose that FitzPatrick thinks that a possible intention to do good is sufficient for permissibility in conjunction with the satisfaction of various non-intentionality involving conditions, such as proportionality and necessity. Otherwise, his view would not establish that it is ever permissible for a doctor to give a suffering patient a lethal dose of morphine, which is supposed to be the benefit of his view over that of the traditional version of the DDE. Therefore, I understand FitzPatrick's view to be that actions are permissible if and only if there is an adequate justification for them, and a justification is adequate if and only if it is such that non-intentionality involving conditions $c_{1}, c_{2}, \ldots c_{n}$ are met and also it appeals only to possible intentions to do good and not intentions to do bad.

In light of this, I want to offer a slightly reconstructed version of the above argument for the claim that intentions to do good are sufficient for permissibility, given that conditions $c_{1}, c_{2}, \ldots c_{n}$ are met.

(i') Given that non-intentionality involving conditions $c_{1}$, $\mathrm{c}_{2}, \ldots \mathrm{c}_{\mathrm{n}}$ are met, a justification for an action is adequate if a good and well-informed agent could act well (i.e., at least not act badly) in performing the action because of that justification for it.

(ii') Intending significant benefit toward innocents as a means or end is morally commendable as such, which typically makes acting on such an intention constitute acting well.

(iii') So, given that conditions $c_{1}, c_{2}, \ldots c_{n}$ are met, an adequate justification of action typically can be such that an agent who performed the action because of that justification would be engaging in the intention of significant benefit toward innocents as a means or as an end.

I believe that FitzPatrick would accept (i') and (ii'), and therefore also (iii'). With the two new premises (i') and (ii'), we conclude that if the non-intentionality involving conditions on permissibility are met, then a possible intention to do good is typically sufficient for justification and therefore permissibility.

However, the problem with this argument is that there is a parallel argument for the conclusion that a possible intention to do bad is sufficient for the impermissibility of an action. If an act is justified-in the sense of having a sufficient set of reasons for its permissibility-because there is a possible agent who could undertake the action while intending the good effects and not the bad effects, then it is unclear why an act would not be unjustified-in the sense of having a sufficient set of reasons for its impermissibility-because there is a possible agent who could undertake the action while intending the bad effects. For presentational clarity, let us call an 'anti-justification' a set of reasons sufficient for an act to be unjustified and hence impermissible.

Why might we think that there are such things as antijustifications that can involve intentions to do bad? Well, let us consider how FitzPatrick connects justification to permissibility and intention:
It is part of the concept of a practical justification for action that an adequate justification would be one that an otherwise good person could act on without thereby acting badly. If a proposed justification failed this condition, and its being taken seriously and acted upon would involve an otherwise good agent in something morally problematic enough that she will thereby be acting badly, then in what sense could it seriously be thought to be an adequate justification? The whole point of a practical justification is to show that the action in question is one that could legitimately be pursued for the reasons given in the justification [8, p. 102].

A justification is a set of reasons that shows the action can be performed with good character and produces a positive outcome in the ways specified by the non-intentionality involving conditions. An intention to do good is a feature of acting well and hence not acting badly. A permissible action is one that could be done while acting well, thus a permissible action is one that could be done with good intention.

Yet, by this same token an anti-justification would consist in a set of reasons that shows the action can be performed by a generally bad agent who acts badly in acting for the reasons constituting the anti-justification. If a bad agent could have an intention to do bad in performing a certain act, then that counts morally against that act. Whatever the intentions of the actual agent who performs the act, we appeal to a possible agent's intentions for the unjustification of the act itself. That there is a possible agent with such an intention shows that the act can be done with bad character and therefore has moral reasons against it such that the act is unjustified and hence impermissible.

Given the concept of an anti-justification, we can mirror FitzPatrick's defense of the DDE-Possible in order to support DDE-Possible*:

The DDE-Possible* does not in fact link the moral impermissibility of an act with the token intentions with which a given agent would be acting. Rather, it links the impermissibility of a certain type of act with the existence of an anti-justification in terms of either an end that is not sufficiently worthy or a sufficiently worthy end that can be pursued through so acting while intending something illicit as means.

This constitutes the claim that given that the end is sufficiently worthy, and therefore clause $\left(2^{*}\right)$ of DDE-Possible* is not satisfied, then an act is impermissible given clause $\left(1^{*}\right)$ is satisfied.

To bring out the analogy further, we can construct an argument linking anti-justification and impermissibility that mirrors the argument linking permissibility to justification that we constructed on behalf of FitzPatrick. To make the mirror image argument we take premise (ii) from FitzPatrick's original argument, and for the other claims we simply substitute terms for their normative opposites-'anti-justification' for 'justification', 'anti-justified' for 'justified', 'impermissible' for 'permissible', 'bad' for 'good', 'badly' for 'well', and so on. Here is the argument: 
$\left(i^{*}\right)$ Given that conditions $c_{1}, c_{2}, \ldots c_{n}$ are met, an antijustification for an action is adequate if a bad and well-informed agent could act badly (i.e., at least not act well) in performing the action because of that antijustification for it.

(ii*) Intending significant harm toward innocents as a means or end is deeply morally problematic as such, which typically makes acting on such an intention constitute acting badly.

(iii*) So, given that conditions $c_{1}, c_{2}, \ldots c_{n}$ are met, an adequate anti-justification of action typically can be such that an agent who performed the action because of that anti-justification would be engaging in the intention of significant harm toward innocents as a means or as an end.

If acting on a set of reasons would constitute the agent acting badly, that is sufficient for that set of reasons to form an ant-justification for the action. An intention to do bad is normally such that acting on it would constitute acting badly. Hence, in normal circumstance an adequate antijustification is one that appeals to a possible intention to do bad, and therefore the presence of a possible intention to do bad is sufficient for impermissibility. This is enough to generate the contradiction with DDE-Possible.

If possible intentions to do good are supposed to track moral reasons for an action, then possible intentions to do bad equally track moral reasons against an action. The reasoning supporting DDE-Possible also supports DDE-Possible*, but the two lead to contradiction. Therefore, it appears that DDE-Possible should be abandoned. At the very least, the proponent owes us an explanation as to why there is a relevant moral asymmetry between intentions to do good and those to do bad. I am skeptical that there is one to be found.

\section{Acknowledgement}

For their helpful feedback on various drafts I would like to thank Ben Bronner and Frances Kamm.

\section{Disclosure of interest}

The authors declare that they have no competing interest.

\section{References}

[1] Mangan J. An historical analysis of the principle of double effect. Theological Stud 1949;10:41-61.

[2] Rachels J. More impertinent distinctions and a defense of active euthanasia. In: Steinbock B, Norcross A, editors. Killing and letting die. 2nd ed. Fordham University Press; 1994. p. 139-54.

[3] Thomson JJ. Physician-assisted suicide: two moral arguments. Ethics 1999;109:497-518.

[4] Scanlon T-M. Moral dimensions: permissibility, meaning, blame. Harvard University Press; 2008.

[5] Kamm F-M. Terrorism, and intending evil. In: Ethics for enemies: terror, torture, and war. Oxford University Press; 2011. p. $73-118$.

[6] FitzPatrick W. Acts, intentions and moral permissibility: in defense of the doctrine of double effect. Analysis 2003;63(4):317-21.

[7] Kamm F-M. Four-step arguments for physician-assisted suicide and euthanasia. In: Bioethical prescriptions: to create, end, choose, and improve lives. Oxford University Press; 2013. p. 53-83.

[8] FitzPatrick W. Intention, permissibility and double effect. In: Timmons M, editor. Oxford studies in normative ethics, 2. Oxford University Press; 2012. p. 97-127.

[9] FitzPatrick W. The doctrine of double effect: intention and permissibility. Philosophy Compass 2012;7(3):183-96. 